\title{
Comparative effects of intramyocardial autotransplantation of different bone marrow cells upon outcomes of experimental myocardial infarction in rabbits
}

Vladimir V. Davydenko', Andrey A. Matyukov', Timur D. Vlasov', Natalya V. Tsupkina ${ }^{2}$, Anatoly N. Yalfimov Georgy P. Pinaev ${ }^{2}$, Khalida K. Amineva $^{1}$

${ }^{1}$ FirstSt.Petersburg State I.Pavlov Medical University

${ }^{2}$ Institute of Cytology, Russian Academy of Sciences, St.Petersburg

${ }^{3}$ Russian Center of Radiology and Surgical Technologies, St.Petersburg

Prof.Dr. V.V.Davydenko, L.Tolstoy St, 6/8, The First St. Petersburg State I. Pavlov Medical University, St. Petersburg, 197022, Russia
Phone: +7-911-994-23-41

E-mail:kuzet@mail.ru

\section{Summary}

Over the last decade, different cell therapy options have been tested to improve treatment of myocardial infarction (MI), including cardiomyoplastics. Autologous bone marrow is a widely used source of therapeutic cell preparations, i.e., freshly isolated mononuclear cell fraction (MF), or cultured multipotent mesenchymal stromal cells (MMSC). The aim of our pilot study was to compare short- and long-term consequences of intramyocardial MF and MMSC transplantation upon clinical course and outcome of experimental MI. Materials and methods: The experiments were performed with male Chinchilla rabbits of $2.8 \pm 0.2 \mathrm{~kg}$ weight. MI was modelled by ligation of anterior descendent left coronary artery. Mononuclear cell fraction was obtained from the bone marrow aspirate. MMSC cell culture was grown by MF cell passages in MEM medium with $10 \%$ fetal calf serum. Intramyocardial injections of MF or MMSC suspensions were performed into 6 points of the infarcted area. The surviving animals were divided in four groups, each consisting of 13 rabbits: group 1 (controls), group 2 (placebo-treated), group 3 (MMSC injections), and group 4 (MF injections). Electrocardiography (ECG) and echo-cardiography were carried out in all animals before surgery, during 1 mo and 1 year after surgery. Myocardial perfusion rates were assessed with SPECT technique. IM dimensions (perfusion areas) were determined by means of staining heart sections with 2,3,5-TTC. Routine histology of myocardial sections was also performed. Vascularization rates of different myocardial areas were assessed in similar way.

\section{Results}

Intramyocardial transplantation of autologous bone marrow cells (MF and MMSC) into the area of rabbit experimental MI during the acute phase has changed natural process development and resulted in principally different morpho-functional outcomes. Ten days after coronary occlusion, all animals exhibited pronounced perfusion decrease in infarcted anterior wall of LV $(p<0,05)$. However, the animals, treated with MMSC or MF showed less impaired perfusion rates than in control or placebo groups $(\mathrm{p}<0.05)$. 1.5 months after treatment, a gradual recovery of mean perfusion rates was observed in damaged myocardium in MMSC and MF-treated groups. These changes were confirmed by perfusion tomoscyntigra- 
phy of myocardium at 1.5 and 12 months after surgery. Histological studies have shown that, after MMSC transplantation, a pattern of microfocal cardiosclerosis was observed, followed by recovery of myocardial structure, whereas MF injections were followed by development of fibrotic aneurism affecting both left and right ventricles. One year after surgical intervention, a more expressed positive effect of MMSC transplantation was observed, i.e., nearly full recovery of all functional parameters (LV ejection fraction; EDSLV, end LV diastolic size; blood flow rates in ascending aorta) at 12 months post-surgery $(p<0.05)$, and absence of akinetic areas.

\section{Conclusions}

MMSC injections were associated with pronounced therapeutic effect, by reducing myocardium damage area. By the contrary, MF transplantation showed a negative effect, expanding myocardium damage area and impairing systolic function indices. Both MMSC and MF intramyocardial transplantation display neoangiogenesis stimulation and perfusion improvement in rabbit experimental infarction area.

\section{Keywords}

myocardial infarction, experimental, bone marrow, mononuclear cells, mesenchymal stem cells, therapeutic injections, myocardial functions, histology.

\section{Introduction}

Myocardial infarction (MI) is a common reason of death and disability worldwide. Over the last decade, different cell therapy options have been tested to improve efficiency of MI treatment, including the s.c. cardiomyoplastics. Various cells are proposed to be used for this purpose. Autologous bone marrow is a widely used source of therapeutic cell preparations, thus providing freshly isolated mononuclear cell fraction (MF), or cultured multipotent mesenchimal stromal cells (MMSC). Meanwhile, existing works concerning clinical effects of MF and MMSC transplantation in acute MI yield controversial results $[6,11,16,24,26,29,31]$, thus necessitating further studies and getting experience in this area.

\section{The aim of the study}

The aim of our experimental study was to compare the effects of intramyocardial MF and MMSC transplantation upon clinical course and outcome of MI, using a rabbit model during prolonged observation terms by using complex of modern functional and morphological study.

\section{Materials and methods}

The experiments were performed with male Chinchilla rabbits of $2.8 \pm 0.2 \mathrm{~kg}$ weight, aged 3 - 4 months. All experimental procedures have been carried out in accordance with guidelines of local Ethical Committee at the First St.Petersburg I.Pavlov State Medical University.

\section{Isolation, characterization, and morphological description of bone marrow cells}

Bone marrow aspirate $(10 \pm 1 \mathrm{~mL})$ was obtained from a rabbit by iliac puncture, following premedication with Droperidol (0.5 mg/kg, Xylasine, $14 \mathrm{mg} / \mathrm{kg}$ body mass), and local anesthesia with 0.5 per cent Novocaine, and placed into a tube containing CPDS (citrate phosphate dextrose solution, Terumo, Japan). Mononuclear cell fraction was obtained by means of centrifugation (1600 g, $20 \mathrm{~min}$ ) Percoll density gradient $(63 \%)$. Interphase cell fraction containing nucleated cells was washed in $\mathrm{Ca}^{2+}$ and $\mathrm{Mg}^{2+}$-free Hanks' solution (Gibco, USA), and span down by centrifuging. MMSC cell culture was obtained by MF cell passaging in a-MEM medium (ICN, USA) with 10 per cent fetal calf serum (Hyclone, New Zealand) supplied with gentamycin sulfate (50 $\mathrm{mcg} / \mathrm{mL}$; Invitrogen, Great Britain) in a $\mathrm{CO}_{2}$ incubator, at 5 per cent $\mathrm{CO}_{2}$ and $100 \%$ humidity for three weeks. The medium was changed twice a week. Ascorbic acid (ICN, USA) was added at a final concentration of $50 \mathrm{mcg} / \mathrm{mL}$ after first medium change. After reaching a semi-confluent state, the cells were reinoculated by means of $0.25 \%$ trypsin solution (Gibco, USA), and EDTA (0.02\%, Gibco, USA). Before being transplanted, the cultured cells did not display any signs of spontaneous osteogenic differentiation, as evidenced by negative staining for alkaline phosphatase with a standard BCIP-NBT reagent (5-bromine-4-chloride-3-indolyl phosphate/ nitroblue tetrazolium, Sigma, USA), or any features of adipocytic transformation detectable with Sudan III/IV mixture (BDH Chemicals Ltd, Great Britain). Meanwhile, special studies with specific induction of differentiation to osteogenic and adipocytic lineage have shown their multipotency, i.e., the cultivated cells had typical MMSC characteristics. 
In some animals, MNC or MMSC were stained prior to transplant with Hoechst nuclear fluorescent dye (Sigma, USA, final concentration of $1 \mathrm{mcg} / \mathrm{mL}$ ), by shaking for 60 $\min$ in a $\mathrm{CO}_{2}$ incubator.

Nucleated marrow cells were counted in Buerker chamber, and their viability was assessed with Trypan Blue solution (Labtech, Russia). The cells labelled with Hoechst dye were detected by their blue nuclear fluorescence upon microscopy, using an «Axioscope» (Zeiss, Germany).

\section{Experimental modelling and treatment of myocardial infarction}

The rabbits were subjected to a left-sided thoracotomy under mechanical ventilation of lungs, followed by ligation of anterior descendent left coronary artery at a distance of $1 \mathrm{~cm}$ from the heart apex (Fig. 1, A, B). Ten minutes after the coronary occlusion, intramyocardial injections of $\mathrm{ME}$ or MMSC suspensions were performed into 6 points of the presumed infarction area, using insulin syringes, at a mean cell number of $2 \pm 0.2 \times 10^{6}$ in $0.4 \mathrm{~mL}$ of a-MEM growth medium (modified Eagle medium), or with equivalent volumes of culture medium (placebo treatment), as shown in Fig. 1 C, D. Control animals were not subjected to myocardial injections. Surgical wounds were closed in layers, pneumothorax being eliminated by means of active air aspiration from the pleural cavity. The surviving animals were classified in four groups, each consisting of 13 animals, i.e., Group 1, (controls), Group 2 (placebo-treated), Group 3 (MMSC injections), and Group 4 (MF injections). Subgroups of ten animals were observed for 1 year after the surgery.
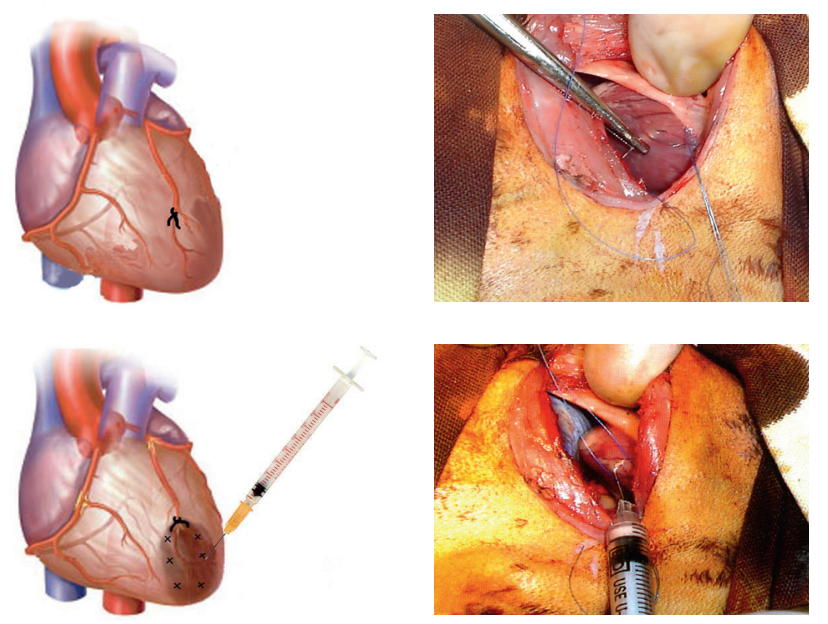

Figure 1. Modelling and treatment of myocardial infarction in rabbits: A - ligation of left anterior descendent coronary artery, B - a view of surgical area, C - topography of intramyocardial injections of marrow cells into the infarcted area; D - a view of surgical area

\section{Detection of labelled cells in the myocardium}

Twenty days after the surgical intervention, the subgroups of three rabbits from Groups 3 and 4 (subjected to myocardial injections) were sacrificed (this term was limited by the life-span of detectable fluorochrome in the cells). The hearts were teased in two parts (basal and apical), in order to get sections at the level of arterial ligature perpendicular to long axis of the heart. Apical part of the heart was pulped and treated with trypsin-collagenase enzyme mixture (Sigma, USA). The dissociated cells were collected by centrifugation, placed onto the microscopic slide, and the proportion of labeled cells have been counted.

\section{Electrocardiography (ECG)}

ECG was carried out in all animals before surgery, at the days $+3,+7,+30$, and one year after surgery. The results were evaluated by the $2^{\text {nd }}$ standard lead on an ECG.

\section{Heart ultrasonography}

EchoCG was performed with a Sequoia 512 echocardiograph (Acuson, USA), using a linear $13 \mathrm{MGz}$ transducer, according to a standard detection technique. EchoCG was performed in all cases before the surgery, at day +14 , and 1 year after the surgery. The procedure was carried out in parallel with ECG recording. The end-diastolic size of left ventricle was registered in M-scanning regimen (EDSLV, mm). Left ventricular systolic function was registered by means of $2 \mathrm{D}$ scanning, from the apical access, in four-chamber and two-chamber positions. EF percentage calculations were made by means of a modified Simpson disc method, using the built-in software of the sonographic device. Aortal blood flow velocity was evaluated at the level of aortal valve (VAo, $\mathrm{m} / \mathrm{sec}$ ), using impulse-wave Doppler sonography. Dynamic features of the left ventricular wall were also studied in intervention/ infarction area, e.g., dyskinesia, hypokinesia, akinesia, calcification, or ossification in the areas of transplantation.

\section{Myocardial perfusion evaluation}

Perfusion rates were assessed with SPECT technique, using radiopharmaceutical tracer (RP) Myoview (Nycomed, Great Britain) labelled with Tc-99m. RP was injected, at a single dose of $30-50 \mathrm{MBq}$, into marginal ear vein via a peripheral catheter. 10 to $15 \mathrm{~min}$ after injection, a SPECT evaluation was performed by double-detector gamma chamber E.Cam. var (Siemens, Germany). To get quantitative values for myocardial perfusion rates, a ratio of mean RP accumulation in damaged versus reference areas was calculated in every case, as arbitrary units (Fig. 2). Uniformity of perfusion was determined as a minimum-to-maximum ratios (in pixels) for damaged and reference areas. The study was performed before surgical intervention, at day +10 , and at $1,5,6$, and 12 months after surgery in all groups of animals. 


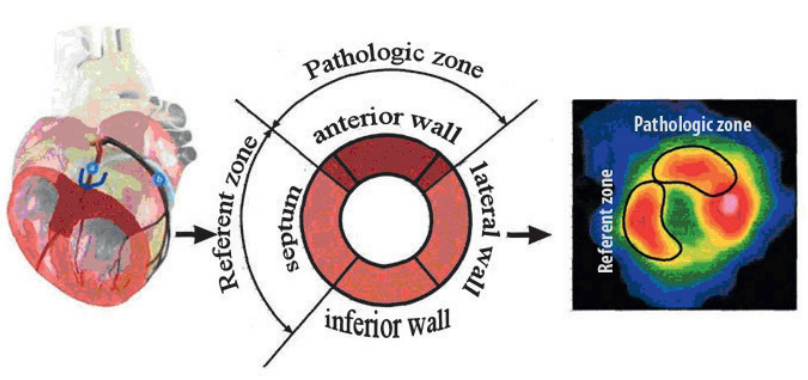

Figure 2. SPECT visualization of left heart ventricle of rabbit. $A$, transverse heart projection at the level of ligated left anterior descendent coronary artery; B, a sketch of left ventricle with designation of its walls and localization of damaged and reference areas; C, perfusion SPECT tomography of the left ventricle of rabbit, with indication of reference zone (non-damaged myocardium area) and pathological zone (infarction localization area)

\section{Sizing of infarcted area, LV dilatation measurements, histological studies}

Dimensions of an experimental IM were determined by means of 2,3,5-triphenyltetrazolium chloride (TTC) staining of the heart sections, thus allowing to discern irreversibly damaged myocardial tissue from viable myocardium. Moreover, a routine histological evaluation was performed. All the animals surviving for 12 months post-surgery were subjected to euthanasia, followed by immediate heart extraction. The organ was rinsed in physiological saline and sectioned transversally with a special device below the ligature level into three segments of equal thickness, i.e., apical (1), middle (2), and basal sections (3), as shown in Fig. 3A.

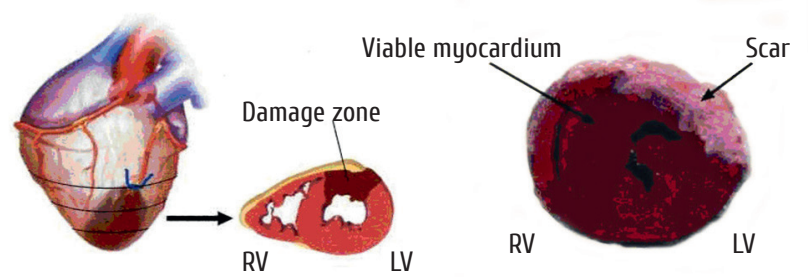

Figure 3. A scheme of residual myocardial damage assessment at 12 months post-treatment. $A$, sectioning of damaged myocardial area into three segments (apical, middle and basal); $B$, evaluation of post-infarction myocardial scarring by means of 1,3,5-TTC staining. Abbreviations: LV, left ventricle; $R V$, right heart ventricle.
In a half of all animals, the heart segments were then placed to $1 \%$ solution of TTC (ICN, USA) for $15 \mathrm{~min}$. at $37^{\circ} \mathrm{C}, \mathrm{pH}$ 7.4. After development of bright-red color in viable myocardium, the stained heart segments were photographed by digital camera (Olimpus 2020, Japan), and the images were stored and processed by Adobe Photoshop CS2 software (Fig. 3B). For the second half of animals, the heart sections were fixed in $10 \%$ formaldehyde solution for 4 days followed by mounting in paraffin and preparing $7-\mathrm{mcm}$ slices, using a routine technique. The histological samples were stained by HE (hematoxylin and eosin) and Mallory dye, thus allowing of discerning various types of connective tissues. Histological examinations were performed with a "BioLam" microscope (Russia). A grade of left ventricular dilatation ( $\mathrm{LV}$ dilatation index) was determined as a ratio of $\mathrm{LV}$ lumen in TTC-positive heart segments to myocardial tissue area in both ventricles. This arbitrary index was calculated for each of three segments, and a mean value was then derived.

\section{Quantitative evaluation of vascularization in damaged myocardial area}

We have examined the borderline areas adjacent to the myocardial scars. Each tissue specimen was routinely stained by Mallory, and five consequent microscopic fields were evaluated at a 400x magnification. We performed separate counts of regulated-type vessels, i.e., arterioles, capillaries, venules, as well as non-regulated type-sinusoids, followed by calculating a mean blood vessel number per microscopic field.

\section{Safety evaluation of approaches for angiogenesis stimulation in ischemic myocardium}

To assess safety of cell transplantation in the studied groups of animals, we compared some general parameters, e.g., intra- and post-surgical mortality, incidence of arrhythmia and septic/inflammatory complications early after surgery. Condition of heart and internal organs was macroscopically evaluated by pathoanathomical obduction data, looking for occurrence of neoplastic processes, and microscopically evaluated for presence of local pathological changes in the areas of cell injections, in particular, atypically differentiated cells, focal sclerosis, or osteogenesis.

\section{Statistical processing}

We used SPSS software for statistical data processing. With small number of observations, the significance of differences was determined by a non-parametric Wilcoxon-Mann-Whitney criterion. All the data were presented as means \pm SD. The differences by $\mathrm{P}$ values of $\leq 0.05$ were regarded as significant. 


\section{Results}

Detection of labeled cells in damaged myocardium

Twenty days after treatment, both MFs and MMSCs were detectable as fluorescent cells, at, resp., $13+2 \%$ and $11+3 \%$ of initial numbers (Fig. 4).

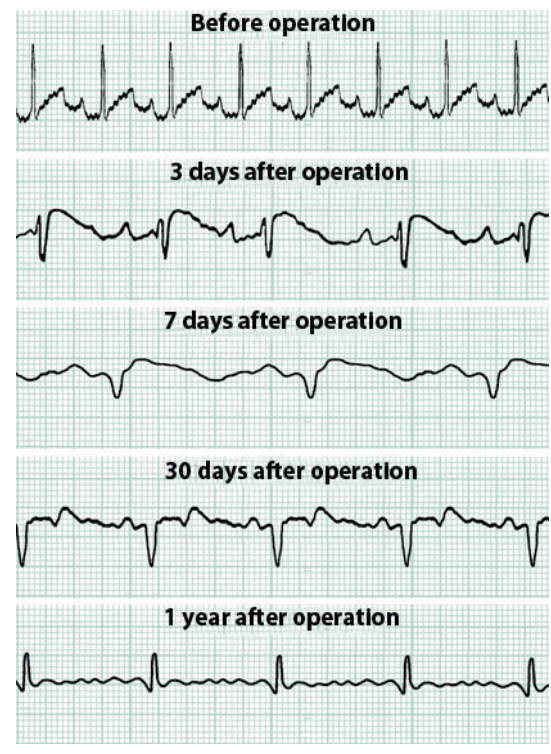

control, placebo
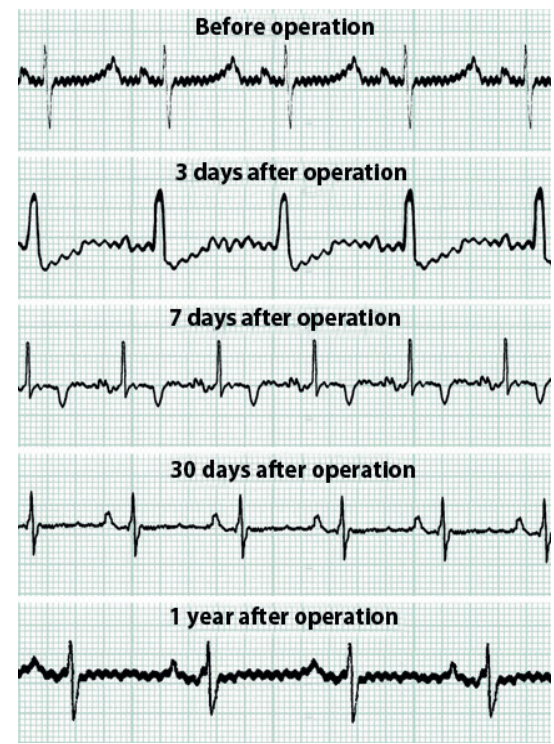

MMSC

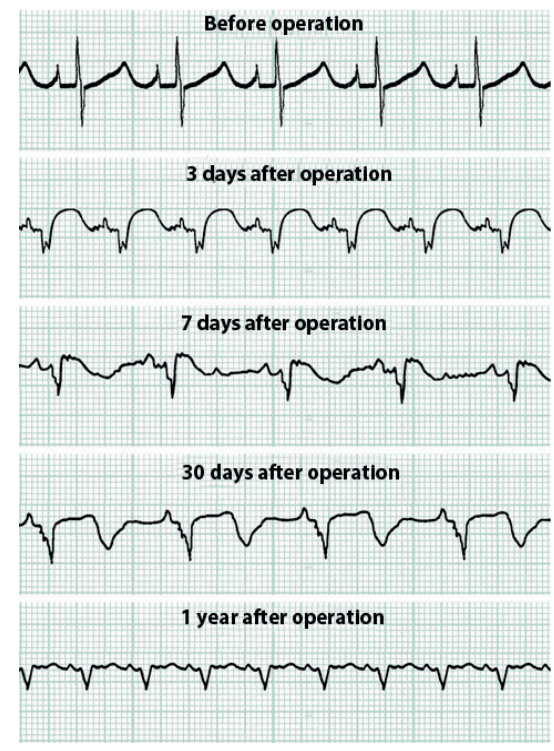

MF

Figure 4. ECG dynamics in studied groups

\section{ECG dynamics in different experimetal groups}

All the animals subjected to experimental coronary occlusion, developed typical ECG features of acute MI with distinct typical dynamics. However, all animals from control (placebo-treated), or MF-transplanted groups exhibited ECG signs of transmural MI, whereas MMSCs-transplant animals displayed only subendocardial myocardial damage (Fig. 5). Heart rate disturbances (atrial extrasystoles) in early postoperative period were developing with similar frequency $(65 \%)$ in all the groups under study, except for MMSC-transplanted animals that showed them 3 times less often (20\%). Twelve months after surgery, ECG patterns in MMSC-treated animals returned to the initial state, as compared with scar changes in ECG observed in MF-treated animals (Fig. 5)

Initial EchoCG parameters did not differ between the groups under study. After the surgical intervention (coronary occlusion), a significant increase of EDSLV was observed, along with diminished EF, VAo. However, these disruptions were dissimilar for different groups, i.e., minimal for MMSC-treated animals and maximal for MNC-treated animals (Table 1, Fig. 6, 7). One year after surgical intervention, a more expressed positive effect of MMSC transplantation was observed, i.e., nearly full recovery of all cardiological parameters $(\mathrm{p}<0,05)$, absence of akinetic areas, that sufficiently differed from appropriate parameters in other groups. In controls and placebo group, the disturbances were long-standing, and a small akinetic area was formed in

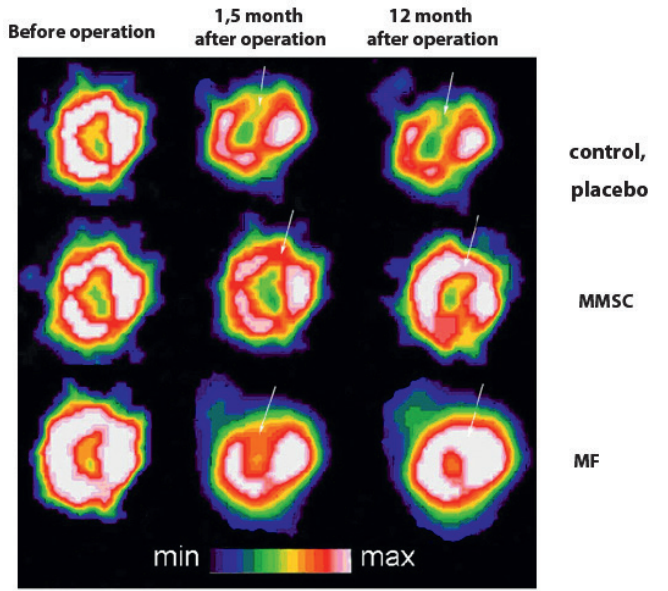

Descriptions: MI-associated perfusion defects are shown by arrows; colour scale shows grade of myocardial perfusion from minimal to maximal values.

Figure 5. Typical changes on perfusion tomoscyntigraphy of myocardium in the groups under study, according to SPECT data before surgery, 1.5 , and 12 months after surgery.

the apical segment. The most negative changes were detected among animals transplanted with MNC, which revealed drastic decrease in LV systolic function, increased LV size, development of extended akinetic areas, as compared with group 3, controls, and placebo group ( $\mathrm{p}<0,05)$ (Table 1, Fig. 6, 7). 


\begin{tabular}{|c|c|c|c|c|c|c|c|c|c|}
\hline \multirow[t]{3}{*}{ Groups } & \multicolumn{9}{|c|}{ Parameters and terms of the study } \\
\hline & \multicolumn{3}{|l|}{$E F, \%$} & \multicolumn{3}{|c|}{ EDSLV, mm } & \multicolumn{3}{|c|}{$\mathrm{V} \mathrm{Ao}, \mathrm{m} / \mathrm{sec}$} \\
\hline & $\begin{array}{l}\text { Initial } \\
\text { values }\end{array}$ & $\begin{array}{l}14 \text { days } \\
\text { after } \\
\text { surgery }\end{array}$ & $\begin{array}{l}12 \\
\text { months } \\
\text { after } \\
\text { surgery }\end{array}$ & $\begin{array}{l}\text { Initial } \\
\text { values }\end{array}$ & $\begin{array}{l}14 \text { days } \\
\text { after } \\
\text { surgery }\end{array}$ & $\begin{array}{l}12 \\
\text { months } \\
\text { after } \\
\text { surgery }\end{array}$ & $\begin{array}{l}\text { Initial } \\
\text { values }\end{array}$ & $\begin{array}{l}14 \text { days } \\
\text { after } \\
\text { surgery }\end{array}$ & $\begin{array}{l}12 \text { months } \\
\text { after } \\
\text { surgery }\end{array}$ \\
\hline №1 (controls) & $62.2 \pm 4.6$ & $45.8 \pm 6.1$ & $46.5 \pm 6.4$ & $14.4 \pm 1.0$ & $17.0 \pm 1.4$ & $16.9 \pm 0.8$ & $95 \pm 4$ & $57 \pm 6$ & $71 \pm 4$ \\
\hline №2 (placebo) & $64.9 \pm 4.3$ & $46.7 \pm 3.5$ & $48.7 \pm 3.9$ & $14.1 \pm 0.4$ & $16.8 \pm 1.2$ & $16.6 \pm 0.8$ & $94 \pm 3$ & $58 \pm 6$ & $73 \pm 6$ \\
\hline №3 (MMSC) & $61.7 \pm 4.0$ & $53.1 \pm 4.8$ & $58.2 \pm 3.1^{\star}$ & $14.7 \pm 0.9$ & $15.2 \pm 0.7$ & $14.9 * \pm 1.2$ & $96 \pm 4$ & $81 \pm 6$ & $89 \pm 4 *$ \\
\hline №4 (MNC) & $59.7 \pm 3.2$ & $38.8 \pm 2.9$ & $28.7^{\star} \pm 4.1$ & $14.9 \pm 1.2$ & $17.9 \pm 0.8$ & $19.8^{\star} \pm 0.9$ & $97 \pm 5$ & $55 \pm 4$ & $45 \pm 3^{*}$ \\
\hline
\end{tabular}

Abbreviations: $L V E F, L V$ ejection fraction; EDSLV, end LV diastolic size; $V$ Ao- blood flow velocity in ascending aorta; *, differences from control group are significant by $p<0,05$.

Table 1. Dynamics of LV systolic parameters from EchoCG data $(\mathrm{M} \pm \mathrm{m})$

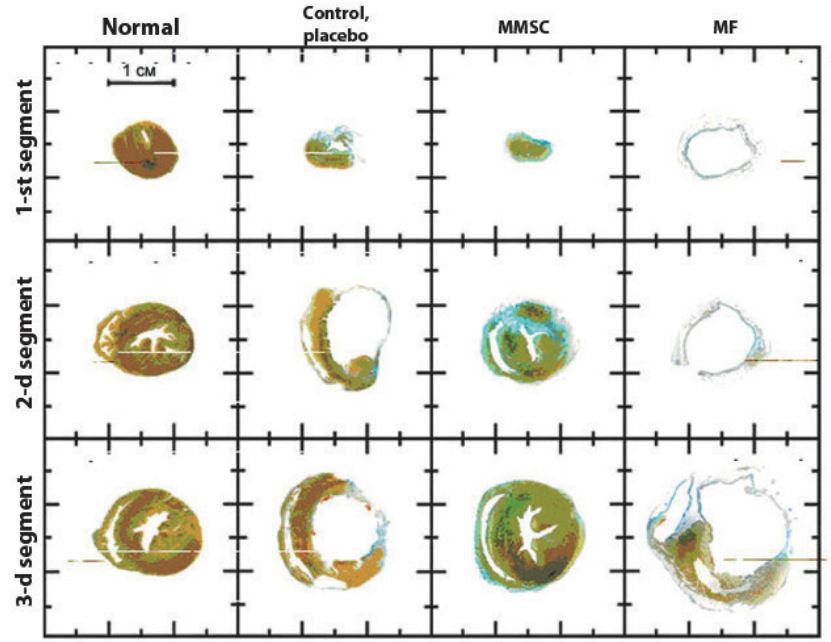

Figure 6. Transverse sections (1, apical; 2 , median; 3 , basal) from infarcted area of the heart wall in different experimental groups (Mallory staining) 12 months after MI modeling/ treatment

\section{Dynamics of myocardial perfusion in the groups under study.}

Cumulative findings concerning dynamics of myocardial perfusion in damaged areas are presented in Table 2. Before surgery, the perfusion parameters in all groups were within reference ranges. Ten days after coronary occlusion, all animals exhibited pronounced perfusion decrease in infarcted anterior wall of LV $(p<0,05)$. However, this decrease var-

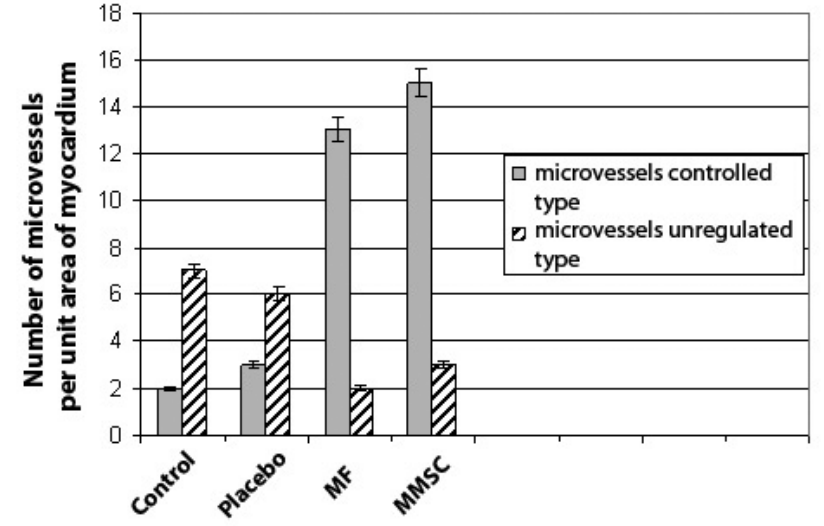

Figure 7. Numbers of regulated vs. sinusoid-type microvessels per a space unit of $\mathrm{Ml}$ area 12 months after modelling and treatment in compared groups of experimental animals.

Ordinate, number of microvessels per a IM space unit; abscissa, groups under study.

ied in different groups of animals, i.e., animals treated with MMSC or MNC showed less impaired perfusion rates than in control or placebo groups $(\mathrm{p}<0,05)$. At 1.5 months after treatment, a gradual recovery of mean perfusion rates was observed in damaged area of myocardium in groups 3 and 4 , reaching the pre-surgical rates by 3 months, in group 3 to a greater extent, without subsequent dynamics. In controls and placebo-treated group, the altered perfusion rates remained at similar levels at all the terms of observation. 


\begin{tabular}{|l|l|l|l|l|l|}
\hline \multirow{2}{*}{ Groups } & \multicolumn{4}{|l|}{ TTC accumulation in damaged area (arb.un.), terms of study } \\
\cline { 2 - 6 } & Before surgery & $\begin{array}{l}10 \text { days after } \\
\text { surgery }\end{array}$ & $\begin{array}{l}1.5 \text { months after } \\
\text { surgery }\end{array}$ & $\begin{array}{l}6 \text { months after } \\
\text { surgery }\end{array}$ & $\begin{array}{l}12 \text { months after } \\
\text { surgery }\end{array}$ \\
\hline Controls & $1.01 \pm 0.01$ & $0.57 \pm 0.02$ & $0.59 \pm 0.04$ & $0.61 \pm 0.02$ & $0.61 \pm 0.04$ \\
\hline Placebo & $1.01 \pm 0,02$ & $0.59 \pm 0.02$ & $0.62 \pm 0.02$ & $0.64 \pm 0.04$ & $0.61 \pm 0.03$ \\
\hline MMSC & $0.98 \pm 0.03$ & $0.81 \pm 0.01 *$ & $0.92 \pm 0.03 *$ & $0.98 \pm 0.02 *$ & $1.02 \pm 0.01^{*}$ \\
\hline MF & $1,00 \pm 0.01$ & $0.75 \pm 0.03 *$ & $0.89 \pm 0.03 *$ & $0.98 \pm 0.03 *$ & $0.99 \pm 0.01^{*}$ \\
\hline
\end{tabular}

Descriptions: arb.units = mean rates of TTC accumulation in damaged area/ mean values of TTC accumulation in reference area; ${ }^{*}$ - significance of differences as compared to control group $(p<0.05)$

Table 2. Dynamics of TTC accumulation in damaged myocardial area after treatment of acute $\mathrm{MI}$ in the groups under study by perfusion data (SPECT evaluation, $\mathrm{M} \pm \mathrm{m}$ ).

\section{Morphometric heart studies}

12 months after experimental MI modeling/ treatment, general macroscopic appearance of rabbit hearts was similar for control and placebo-treated groups, i.e., enlarged heart size, as compared to healthy hearts (intact animals), along with apical aneurism of LV. Distinct scarring of LV anterior wall was evident for the hearts from MMSC-treated animals, however, without evolving aneurysm, and without sufficient increase of the heart size. Heart dimensions among MF-treated animals did significantly exceed normal size, and appropriate heart parameters of healthy rabbits, and the animals from groups 1,2, and 3. The animals transplanted with MF had extendsive aneurysms at the apex and anterior wall of LV (Fig. 9,10,11). Scarring area and LV dilatation index for control group were, resp., $20.2 \pm 1.9 \%$, and $0.19 \pm 0.02$; $20,8 \pm 1.6 \%$ and $0.18 \pm 0.03$ for placebo group; $35.8 \pm 1.6 \%$ and $0.34 \pm 0.03$ for MF-transplanted group,. The animals treated with MMSCs exhibited the best characteristics, i.e., $6.0 \pm 2.6 \%$ and $0.11 \pm 0.02$ (Fig. 12).

\section{Histological pattern of myocardium}

It was shown that intramyocardial MMSC vs. MF transplantation resulted, after 12 months, in the development of principally different heart morphology as compared to control or placebo groups of animals. After MMSC transplantation, a pattern of microfocal cardiosclerosis was observed, followed by recovery of myocardial structure, whereas MF injections were followed by development of fibrotic aneurism affecting both left and right ventricles.

\section{Quantitative myocardial vascularization}

12 months after MI modeling/treatment, a significant difference was revealed in vascularization patterns of damaged myocardium in the studied groups, i.e., the total microvessel numbers per 1 microscopic field were, resp., 15 $\pm 3,13 \pm 3,7 \pm 1$ and $6 \pm 2$ for groups treated with MMSCs, MFs, controls and placebo-treated animals. After intramyocardial autotransplantation of bone marrow, the microvessel density in the area was not only increased over controls or placebo groups $(\mathrm{p}<0.05)$, but it exhibited a distinct type of microvessels showing a regulated type-wall, whereas control group recovered with development of sinusoid-type microvessels.

\section{Safety evaluation}

\section{of neoangiogenesis stimulation in ischemic myocardium}

Intra- and post-operative mortality in all the studied groups did not significantly differ (a mean of $10 \pm 3 \%$ и $10 \pm 4 \%$ ). Incidence of septic and inflammatory complications in the intervention area was, in general, significantly lower $(\mathrm{p}<0.05)$ among intramyocardially cell-treated animals (1) than in control or placebo group (3). No differences were here noted between MF and MMSC-treated groups. At macroscopic examination one year after surgical intervention, both groups of cell-treated animals did not show any signs of malignant neoplasia. Local examination of myocardium at the locations of cell injections did not reveal any cells with atypical differentiation (osteogenic or chondrogenic tissues).

\section{Discussion}

Rabbit model of myocardial infarction induced by ligation of anterior descendent left coronary artery proved to be a convenient and demonstrative technique for evaluation of therapeutic angiogenesis, testing the effects of vascular growth factors and cellular therapy [14]. The results obtained in present study have shown that intramyocardial transplantation of autologous bone marrow cells (MF versus MMSC) into the MI area in rabbits during acute period may consid- 
erably change the natural process of MI development and exerts different morpho-functional effects upon the damaged tissues.

MMSC transplantation, as compared to controls and placebo, was associated with definite reduction of the myocardial damage, and later (12 months after MI) this group of animals exhibited normalization of heart systolic function, ECG, myocardial perfusion. Meanwhile, upon morphological examination, the infracted area was represented by fine focal cardiosclerosis, without aneurism formation. The detected changes might have been caused by paracrine effect of transplanted cells and, probably, by their differentiation into various myocardial structures. At the first phase of MI characterized by death of the cardiomyocytes, the transplanted MMSC are able to inhibit apoptosis and produce a cytoprotective effect, thus allowing cardiomyocytes and transplanted cells to survive the ischemic state $[6,16,30]$. Moreover, the detected changes might be associated with changing degree of inflammatory response, due to effect of the transplant upon the cytokine profile. In the course of inflammation caused by ischemic damage of myocardium, there are two cytokine groups: pro-inflammatory factors (interleukin-1 $\alpha$, $1 ß, 6,8$, tumor necrosis factor- $\alpha, \beta$ and others) mostly secreted by macrophages and neutrophils, and anti-inflammatory molecules (interleukin-4, 10, transforming growth factor- $\beta$ and others), mainly released by lymphocytes, monocytes and macrophages. It was shown in vitro that bone marrow MMSC, along with anti-inflammatory cytokines (interleukin-1 $\alpha, 1 \beta, 6,7,8$, tumor necrosis factor- $\alpha, \beta)$ produce a broad spectrum of anti-inflammatory cytokines (interleukin- 4,10 , transforming growth factor- $\beta$ ), as well as specific receptors for interleukin-1 $\alpha, 1 ß, 1,3,4,6,7,8$, tumor necrosis factor- $\alpha, \beta$ [22]. Moreover, it has been shown that the bone marrow MMSC secrete different chemokines: MCP-1, RANTES, MIP-1alpha [23]. Most probably, such cytokine profile may induce significant populational changes, e.g., quantitative increase of macrophages, lymphocytes and monocytes that are able to secrete anti-inflammatory cytokines. This mechanism allows to reduce the degree of inflammatory response and the damaged area.

Progression of the small-focal myocardial infarction and normalization of systolic functions after BM MMSC transplantation, as shown in our study, can be also explained by potential ability of transplanted cells to differentiate into cardiomyocytes. However, an opportunity of BM MMSCs differentiation into cardiomyocites remains problematic. Most researchers note the ability of bone marrow MMSC to acquire cardiomyocyte-like phenotypes after transplantation into the damaged myocardium, as shown by synthesis of $a$-actinin, troponin-T, tropomyosin. However, they have not revealed developing intercellular structures and/or contractile functions $[20,21,27]$.

Thus, the changes in myocardial morphology and function after MMSC transplantation may be caused by their cytoprotective activity and ability to reduce the inflammatory response during acute infarction phase. By the contrary, intramyocardial MF transplantation, as compared to control and placebo groups, caused alterations of myocardial contractile function, expanding damage area, resulting into significant left ventricular fibroid aneurysms. Such effect is probably determined by MF ability to intensify inflammatory response, due to changing quantitative and qualitative cytokine profile in the damaged area, following direct massive injections of leukocytes. The bone marrow MFs constitute a heterogeneous population, containing mesenchymal stromal cells, hematopoietic stem cells, progenitor endothelial cells, as well as myeloid and lymphoid cells at different stages of maturation. There is an abundance of mature leukocytes among the bone marrow MF. Apparently, upon entering the ischemic myocardium, the MF start to release a variety of proteolytic enzymes and anti-inflammatory cytokines which attract blood cells to the altered areas, thus intensifying the inflammatory response [8]. The key point of myocardial repair is based on equilibrium between extracellular matrix degradation (needed for cell migration), and its resynthesis by the cells migrating to the damaged area. The proteolytic enzymes released by MF lyse intercellular collagen links and activate matrix metalloproteinases. Extracellular matrix degradation and expansion of infarcted area are caused by a cascade of proteolytic reactions. Moreover, the matrix metalloproteinases are also activated by some cytokines, e.g., as interleukin- $1 ß$ и tumor necrosis factor- $\alpha, \beta[9,19]$.

G. Ertl, S. Frantz have shown that dilatation of left ventricle and mortality were less expressed in the mice deficient for interleukin- $1 ß$ than in animals with normal cytokine levels [7]. In addition, proteolytic enzymes released by transplanted MF of bone marrow induce massive death of cardiomyocytes. Cardiac myosin released from necrotized myocardium is a proven potent autoantigen. The autoimmune reactions occur via activation of $\mathrm{T}$ lymphocytes followed by the secondary T-cell induced damage of cardiomyocytes and altered remodeling of extracellular matrix $[2,28]$.

Thus, morphological and functional changes revealed in myocardium after bone marrow MF injections may be caused by excessive intensification of inflammatory response during the hyperacute phase of MI.

The results of our study indicate that intramyocardial transplantation of MMSC and MF of bone marrow leads to increased vascularization of damage area. We assume that the angiogenic effect of these cells is accomplished by secretion of vascular growth factors and, probably, by differentiation of transplanted cells into cellular components of the vascular wall.

MMSCs are able to secrete angiogenic factors, such as VEGF (vascular endothelial growth factor), bFGF (basic fibroblast growth factor), HGF (hepatocyte growth factor), TGF- $\beta$ (transforming growth factor), angiopoietin-1 [13, 19]. Tang et al. (2005) demonstrated that the BM MMSC transplantation into the ischemic myocardium results into secretion of cytokine SDF-1 (stromal cell derived factor-1), which is a chemoattractant for endothelial cell progenitors and hematopoietic stem cells [22]. Progenitor endothelial cells migrating from peripheral blood into the damaged area are able to transform into mature endothelial cells and participate in angiogenesis [4, 12, 17]. Another mechanism of MMSCs involvement in post-transplant neoangiogenesis in myocardium is connected with their ability to differentiate into 
endothelial cells, smooth muscle cells, pericytes, fibroblasts that subsequently become components of the vascular wall, as shown in several studies $[4,22]$.

Involvement of bone marrow MF in angiogenesis, according to the literature data, is regulated by several mechanisms. First of all, the MF populations, e.g., mesenchymal stromal cells, hematopoietic stem cells, progenitor endothelial cells, as well as immature cells of myeloid and lymphoid series, are secreting various angiogenic factors (VEGF, bFGF, TGF- 3 , PDGF, angiopoietin-1, which stimulate proliferation of vascular endothelium and endothelial progenitors of damaged myocardium $[13,25,30,31]$. Secondly, the MF cells are able to secrete SDF-1 (stromal cell derived factor-1), which is a chemoattractant for progenitor endothelial cells and hematopoietic stem cells [20]. Thirdly, such mesenchymal stromal cells within the MF fraction are able to differentiate into endothelial cells and other vascular structures [22].

Our data differ from other studies that did not show such significant differences after MF and MMSC transplantation to the experimental MI area $[6,13,16,21,25,27,31]$. A probable explanation is that transplantation of bone marrow cells in these studies was performed either in later terms following MI, or the cells were administered by a different route, e.g., via coronary arteries, or intravenously [1,3,5,10,24,29]. A prolonged observation in our study did not register such complications as ossification or formation of angiomas in the cell transplantation area, as previously described [15], neither any neoplastic processes have been registered.

\section{Conclusions}

1. Local intramyocardial transplantation of autologous bone marrow cells (MF and MMSC) into the area of rabbit, when performed in acute phase of experimental MI, was accompanied by changes in the MI development and resulted into different morphofunctional outcomes. I.e., transplantation of mesenchymal stem cells exerted a pronounced therapeutic effect, causing reduction of myocardial damage area and improvement of systolic functional indices. On the contrary, mononuclear cell transplantation produced negative effects, causing expansion of the damaged area and impairment of systolic indices.

2. Both MMSC and MF intramyocardial transplantation display stimulation of neoangiogenesis and improvement of perfusion in the infarcted area.

\section{Conflict of interest}

All the authors have no conflict of interest to declare.

\section{References}

1. Chen Y, Teng X, Chen W et al. Timing of transplantation of autologous bone marrow derived mesenchymal stem cells for treating myocardial infarction. Sci China Life Sci 2014; 57(2): 195-200.
2. Cheng X, Liao YH, Li B et al. Changes of rat lymphocyte proliferation and cytotoxic activity after acute myocardial infarction in vitro. Chin J Pathophysiol 2005; 21(9): 1848-50.

3. Clifford DM, Fisher SA, Brunskill SJ et al. Long-term effects of autologous bone marrow stem cell treatment in acute myocardial infarction: factors that may influence outcomes. PLoS ONE 2012; 7(5): e37373.

4. Davani S, Marandin A, Mersin N et al. Mesenchymal progenitor cells differentiate into an endothelial phenotype, enhance vascular density, and improve heart function in a rat cellular cardiomyoplasty model. Circulation 2003;108 (Suppl 1): 253-58

5. Delewi R, Andriessen A, Tijssen JG et al. Impact of intracoronary cell therapy on left ventricular function in the setting of acute myocardial infarction: a meta-analysis of randomised controlled clinical trials. Heart 2013; 99(4): 225-32.

6. de Macedo Braga LM, Lacchini S, Schaan BD et al. In situ delivery of bone marrow cells and mesenchymal stem cells improves cardiovascular function in hypertensive rats submitted to myocardial infarction. J Biomed Sci 2008; 15(3): 365-74.

7. Ertl G, Frantz S. Healing after myocardial infarction. Cardiovasc Res 2005; 66: 22-32.

8. Frangogiannis NG, Entman ML. Chemokines in myocardial ischemia. Trends Cardiovasc Med 2005; 15(5): 163-9.

9. Frantz S, Ducharme A, Sawyer D et al. Targeted deletion of caspase-1 reduces early mortality and left ventricular dilatation following myocardial infarction. J Mol Cell Cardiol 2003; 35(6): 685-94.

10. Jeevanantham V, Butler M, Saad A et al. Adult bone marrow cell therapy improves survival and induces long-term improvement in cardiac parameters: a systematic review and meta-analysis. Circulation 2012; 126(5): 551-68.

11. Jiang M, He B, Zhang Q et al. Randomized controlled tials on the therapeutic effects of adult progenitor cells for myocardial infarction: meta-analysis. Expert Opin Biol Ther 2010; 10(5): 667-80.

12. Kahn J, Byk T, Jansson-Sjostrand L et al. Overexpression of CXCR4 on human CD34_progenitors increases their proliferation, migration, and NOD/SCID repopulation. Blood 2004; 103: 2942-49.

13. Kamihata $H$, Matsubara $H$, Nishiue $\mathrm{T}$ et al. Implantation of bone marrow mononuclear cells into ischemic myocardium enhances collateral perfusion and regional function via side supply of angioblasts, angiogenic ligands, and cytokines. Circulation 2001; 104: 1046-52.

14. Landau C, Jacobs AK, Haudenschild CC. Intrapericardial basic fibroblast growth factor induces myocardial angiogenesis in a rabbit model of chronic heart ischemia Am Heart J 1995; 129(5): 924-31.

15. Larionov PM, Sergeevichev DS, Chernyavskii AM et al. Angiomatosis and ectopic ossification in the dog myocardium after intramyocardial implantation of autologous bone 
marrow mononuclears in experimental coronary disease. Bull Exp Biol Med 2009; 147(5): 644-9.

16. Li SR, Qi XY, Hu FL et al. Mechanisms of improvement of left ventricle remodeling by transplanting two kinds of autologous bone marrow stem cells in pigs. Chin Med J 2008; 121(23): 2403-9.

17. Luttun A, Carmeliet G, Carmeliet P. Vascular progenitors: from biology to treatment.// Trends. Cardiovasc Med 2002; 12: 88-96.

18. Matsumoto R, Omura T, Yoshiyama M et al. Vascular endothelial growth factor-expressing mesenchymal stem cell transplantation for the treatment of acute myocardial infarction. Arterioscl Thromb Vasc Biol 2005; 25(6): 1168-73.

19. Pagani FD, Baker LS, Hsi C et al. Left ventricular systolic and diastolic dysfunction after infusion of tumor necrosis factor-alpha in conscious dogs. J Clin Invest 1992; 90: 389-98.

20. Pittenger MF, Martin BJ, Finkel T, Bolli RE. Mesenchymal stem cells and their potential as cardiac therapeutics. Circ Res 2004; 95(1): 9-20.

21. Shake JG, Gruber PJ, Baumgartner WA et al. Mesenchymal stem cell implantation in a swine myocardial infarct model: engraftment and functional effects. Ann Thorac Surg 2002; 73: 1919-26.

22. Tang YL. Autologous mesenchymal stem cells for post-ischemic myocardial repair. Meth Mol Med 2005; 112: 183-92.

23. Vandervelde S, Luyn MJ, Tio RA et al. Signaling factors in stem cell-mediated repair of infarcted myocardium. Mol Cell Cardiol 2005; 39(2): 363-76.

24. van der Spoel TI, Jansen of Lorkeers SJ, Agostoni P et al. Human relevance of pre-clinical studies in stem cell therapy: systematic review and meta-analysis of large animal models of ischaemic heart disease Cardiovasc Res 2011; 91(4): 649-58.

25. Waksman R, Fournadjiev J, Baffour R et al. Transepicardial autologous bone marrow-derived mononuclear cell therapy in a porcine infarcted myocardium. Cardiovasc Radiation Med 2004; 5: 125-31.

26. Wen Y, Chen B, Wang C et al. Bone marrow-derived mononuclear cell therapy for patients with ischemic heart disease and ischemic heart failure Expert Opin Biol Ther 2012; 12(12): 1563-73.

27. Yoon J, Min BG, Kim YH. Differentiation, engraftment and functional effects of pretreated mesenchymal stem cells in a rat myocardial infarct model. Acta Cardiol 2005; 60(3): 277-84.

28. Zhang J, Chen J, Liao YH et al. Myocardial inflammation and remodeling driven by cardiac myosin specific- $\mathrm{T}$ lymphocytes. J Hong Kong Coll Cardiol 2005; 13(2): 130.

29. Zhang H, van Olden C, Sweeney D, Martin-Rendon E. Blood vessel repair and regeneration in the ischaemic heart (review). Open Heart 2014; 1:doi:10.1136/ openhrt-2013-000016

30. Zhang S, Zhang P, Guo J et al. Enhanced cytoprotection and angiogenesis by bone marrow cell transplantation may contribute to improved ischemic myocardial function. Eur J Cardiothoracic Surg 2004; 25: 188-95.

31. Zhang S, Ge J, Sun A et al. Comparison of various kinds of bone marrow stem cells for the repair of infracted myocardium: single clonally purifield non-hematopoietic mesenchymal stem cells serve as a superior source. J Cell Biochem 2006; 99(4): 1132-47.

\title{
| Сравнительные эффекты внутримиокардиальной аутотрансплантации различных видов клеток костного мозга на исходы экспериментального инфаркта миокарда у кроликов
}

\author{
Георгий П. Пинаев ${ }^{2}$ Халида К. Аминева ${ }^{1}$

\begin{abstract}
${ }^{1}$ Первый Санкт-Петербургский государственный медицинский Университет им. И.П.Павлова
${ }^{2}$ Институт цитологии Российской Академии наук, Санкт-Петербург

${ }^{3}$ Российский центр радиологии и хирургических технологий, Санкт-Петербург
\end{abstract}

Владимир В. Давыденко ${ }^{1}$, Андрей А. Матюков ${ }^{1}$, Тимур Д. Власов ${ }^{1}$, Наталия В. Цупкина ${ }^{2}$, Анатолий Н. Ялфимов ${ }^{3}$

\section{Резюме}

Введение. На протяжении последних 10 лет изучались различные варианты клеточной терапии, на- правленной на улучшение результатов лечения инфаркта миокарда (ИМ), включая кардиомиопластику. Аутологичный костный мозг широко применяется в качестве источника изолированных препаратов кле- 